\title{
Spatial Distribution of PCB Dechlorinating Bacteria and Activities in Contaminated Soil
}

\author{
Birthe V. Kjellerup, ${ }^{1}$ Piuly Paul, ${ }^{2}$ Upal Ghosh, ${ }^{2}$ Harold D. May, ${ }^{3}$ and Kevin R. Sowers ${ }^{4,5}$ \\ ${ }^{1}$ Department of Biological Sciences, Goucher College, 1021 Dulaney Valley Road, Baltimore, MD 21204, USA \\ ${ }^{2}$ Department of Civil and Environmental Engineering, University of Maryland Baltimore County, 1000 Hilltop Circle, Baltimore, \\ MD 21250, USA \\ ${ }^{3}$ Department of Microbiology \& Immunology, Medical University of South Carolina, 171 Ashley Avenue, Charleston, SC 29425, USA \\ ${ }^{4}$ Department of Marine Biotechnology, University of Maryland Baltimore County, 701 E. Pratt Street, Baltimore, MD 21202, USA \\ ${ }^{5}$ Institute of Marine and Environmental Technology, Columbus Center, University of Maryland, 701 E. Pratt Street, Baltimore, \\ MD 21202, USA
}

Correspondence should be addressed to Kevin R. Sowers, sowers@umbc.edu

Received 2 December 2011; Accepted 28 February 2012

Academic Editor: Jeffrey L. Howard

Copyright (C) 2012 Birthe V. Kjellerup et al. This is an open access article distributed under the Creative Commons Attribution License, which permits unrestricted use, distribution, and reproduction in any medium, provided the original work is properly cited.

\begin{abstract}
Soil samples contaminated with Aroclor 1260 were analyzed for microbial PCB dechlorination potential, which is the rate-limiting step for complete PCB degradation. The average chlorines per biphenyl varied throughout the site suggesting that different rates of in situ dechlorination had occurred over time. Analysis of PCB transforming (aerobic and anaerobic) microbial communities and dechlorinating potential revealed spatial heterogeneity of both putative PCB transforming phylotypes and dechlorination activity. Some soil samples inhibited PCB dechlorination in active sediment from Baltimore Harbor indicating that metal or organic cocontaminants might cause the observed heterogeneity of in situ dechlorination. Bioaugmentation of soil samples contaminated with PCBs ranging from 4.6 to $265 \mathrm{ppm}$ with a pure culture of the PCB dechlorinating bacterium Dehalobium chlorocoercia DF1 also yielded heterologous results with significant dechlorination of weathered PCBs observed in one location. The detection of indigenous PCB dehalorespiring activity combined with the detection of putative dechlorinating bacteria and biphenyl dioxygenase genes in the soil aggregates suggests that the potential exists for complete mineralization of PCBs in soils. However, in contrast to sediments, the heterologous distribution of microorganisms, PCBs, and inhibitory cocontaminants is a significant challenge for the development of in situ microbial treatment of PCB impacted soils.
\end{abstract}

\section{Introduction}

Polychlorinated biphenyls (PCBs) are persistent organic pollutants that are still present in the environment despite a U.S. production ban in 1976 [1]. Prior to this, commercial mixtures of PCBs (trade name Aroclor in the U.S.) were used for a range of industrial applications such as high-voltage transformers, insulating materials, and hydraulic liquids [2, $3]$. PCBs are hydrophobic with a high affinity for adsorption to soil particles and for bioaccumulation in lipids causing hepato- and immunotoxicity, carcinogenesis, and affecting endocrine organs and reproduction in humans $[4,5]$ and animals [6]. Removal of PCBs from impacted sites has, therefore, been a regulatory priority for several decades [7].
Soils contaminated with PCBs can be found worldwide as a result of industrial activity [8]. However, large heterogeneities in contaminant concentration and microbial populations were observed, when the total concentration of PCBs and other contaminants were evaluated on both macro- and microscales $[9,10]$. In some cases, the reason for the heterogeneity was caused by the source of contamination such as organic contaminants from an aluminum plant, where there was a decreasing contaminant gradient away from the plant [11]. Even in cases without a specific source, the physical and environmental conditions in soil involved in formation of soil aggregates impacted the spatial distribution of PCBs leading to heterogeneity of microbial activity [12, 13]. Despite the physical heterogeneities in soil, prior studies 
have shown that this variability is not a crucial factor for the composition of the microbial soil communities [14]. Previous reports suggested that sites contaminated with weathered PCBs are recalcitrant to microbial dechlorination [15] due to sequestering of PCB molecules in the pores of the soil particles [16]. Desorption of PCBs depends on the partitioning of PCB molecule between the pore water and the associated organic matter as well as the diffusion of the molecules. It has been suggested that formation of strong bonds between the PCB molecule and the soil particles could cause desorption resistance [16].

Complete microbial degradation of PCBs requires anaerobic reductive dechlorination of extensively chlorinated congeners followed by subsequent aerobic cleavage of the biphenyl ring and mineralization of the less extensively chlorinated congeners $[17,18]$. Several anaerobic bacteria within the Chloroflexi have been confirmed to have PCB dechlorinating activity including Dehalococcoides ethanogenes, [19], Dehalococcoides sp. CBDB1 [20], Dehalobium chlorocoercia DF-1, bacterium o-17 [21], and phylotypes SF1 and DH-10 [22]. In contrast, aerobic PCB degradation can be performed by many bacterial species such as Burkholderia xenovorans strain LB400 [23], Rhodococcus sp. strain RHA1 [24], and bacteria utilizing biphenyls are ubiquitously distributed in the environment [25]. Biphenyl 2,3-dioxygenases are considered the key enzymes in the oxidative pathway for PCB degradation, where bphA1 can degrade specific PCB congeners [26] and bphC is involved in extradiol meta cleavage [27]. In the soil environment, bioaugmentation with aerobic PCB degrading bacteria has successfully been applied [28, 29], whereas anaerobic bioaugmentation has previously only shown success in sequential anaerobicaerobic treatment in granular sludge and a mixture of sediment and soil [30].

In this study, the spatial distribution of putative aerobic and anaerobic bacteria involved in PCB transformation was investigated for the first time in PCB-contaminated soil. The indigenous anaerobic dechlorination potential was mapped spatially throughout the site using a fixed grid established for previous sampling events. In addition, the effect of anaerobic bioaugmentation with a PCB dechlorinating microorganism was evaluated.

\section{Materials and Methods}

2.1. Bacterial Cultures for Bioaugmentation. Dehalobium chlorocoercia DF-1 isolated from sediments in Charleston Harbor was maintained in the laboratory as descried previously [31]. D. chlorocoercia dechlorinates doubly flanked in the para or meta positions.

2.2. Sample Collection. Samples were collected from astorm water drainage ditch in Mechanicsburg, PA ranging from its source at $40^{\circ} 13^{\prime} 46.16^{\prime \prime} \mathrm{N}, 76^{\circ} 59^{\prime} 38.51^{\prime \prime} \mathrm{W}$ to approximately 730 meters downstream to $40^{\circ} 14^{\prime} 06.60^{\prime \prime} \mathrm{N}, 76^{\circ} 59^{\prime} 32.50^{\prime \prime} \mathrm{W}$. The open drainage ditch, which collects storm water runoff from the Naval Support Activities base and surrounding offbase properties, extends approximately 2.4 kilometers from

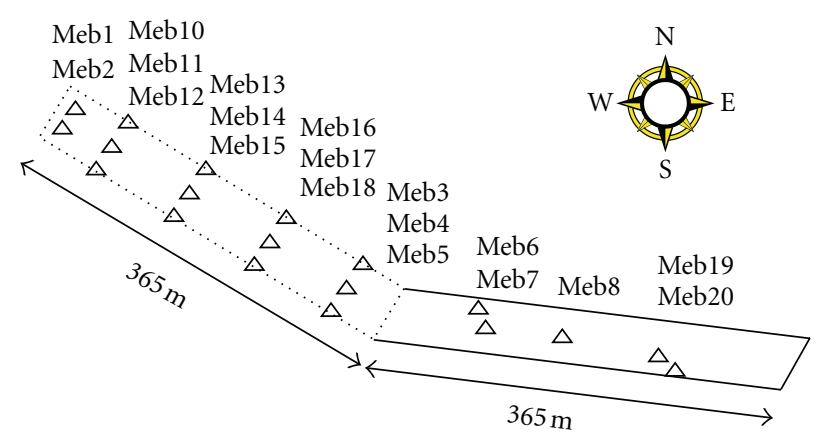

FIgUre 1: Sampling locations in the drainage ditch.

its origin to its confluence with Trindle Spring Run. Samples contaminated with different levels of PCBs were collected with a $60 \mathrm{~cm}$ by $5 \mathrm{~cm}$ (OD) core sampler from the top $30 \mathrm{~cm}$ of soil. In total, 19 soil samples were collected (Figure 1) and stored anaerobically in sealed glass jars at $4^{\circ} \mathrm{C}$ in the dark and processed 1-3 weeks later.

2.3. Extraction and Analysis of PCBs from Soil Samples and Microcosms. The total concentration of PCBs in the samples was measured in sacrificed samples as described previously [32]. Briefly, the samples were weighed prior to extraction, the overlying water was separated from the soil by decanting, and the remaining sample was mixed with anhydrous sodium sulfate. Following the addition of the surrogates PCB-14, PCB-65, and PCB-166, the overlying water samples were shaken in hexane, while the solid samples were extracted by sonication in $25 \mathrm{~mL}$ of $1: 1$ acetone: hexane for six minutes following EPA method 3550B. The extracts were then pooled and solvent exchange was performed to replace the solvents with hexane. PCB cleanup was based on EPA SW846 Methods 3660B (activated copper treatment), and 3630C (silica gel treatment). The volume obtained after cleanup was diluted according to QA protocols, and the PCB congeners were analyzed using an Agilent 6890 Gas Chromatograph equipped with microelectron capture detector.

2.4. Microbial Activity Assays. A microbial dechlorination activity assay was used to determine the potential dechlorination activity of indigenous microbial communities in the soil samples as described previously [33]. Briefly, $10 \mathrm{~mL}$ of low-sulfate mineral F-medium [34] was prepared anaerobically and the congener 2,3,4,5,6-CB (AccuStandard, CT) was added to a final concentration of $50 \mathrm{ppm}$ in acetone (10 $\mu \mathrm{L}$ added). Triplicate cultures were inoculated with $4.0 \mathrm{~g}$ of soil (wet weight). Negative controls were prepared by autoclaving twice for $20 \mathrm{~min}$ at $121^{\circ} \mathrm{C}$ one and three days after inoculation prior to adding $\mathrm{PCB}$. The cultures were incubated at $30^{\circ} \mathrm{C}$ in the dark and $1 \mathrm{~mL}$ subsamples were collected for PCB analysis in an anaerobic glove box after 0 , $52,75,105,130,163$, and 200 days.

Inhibition of the dechlorination activity was evaluated with a modification of the activity assay described above. Sediment from Baltimore Harbor (2 g) with confirmed dechlorination activity was mixed with the test soil sample 
$(2 \mathrm{~g})$ in $\mathrm{E}-\mathrm{Cl}$ medium and analyzed for PCB dechlorination. Sampling for PCB analysis was performed after 0, 50, 75, 100, 150 , and 214 days.

2.5. DNA Extraction. DNA was extracted (in triplicate) by transferring $0.75 \mathrm{~g}$ of soil to a sterile microcentrifuge tube containing approximately $1 \mathrm{~g}$ of $0.1 \mathrm{~mm}$ Zirconia/Silica Beads (BioSpec Products, Inc. OK) followed by addition of $200 \mu \mathrm{L}$ of $1 \mathrm{x}$ TE buffer, $150 \mu \mathrm{L}$ of phosphate buffer $\mathrm{pH}$ $8.0(0.12 \mathrm{M})$ and $150 \mu \mathrm{L} 1 \mathrm{x}$ TS-SDS buffer. The sample and buffers were mixed by hand shaking prior to $30 \mathrm{~s}$ of bead beating at speed "4.5" using a FastPrep120 (QBiogene, CA). Nucleic acid extraction and purification were performed using a phenol/chloroform-based protocol described previously [35].

2.6. Detection and Enumeration of Putative PCB Dechlorinating Bacteria. Enumeration of putative dechlorinating bacteria in the soil samples was performed in triplicate by a competitive PCR assay as described previously [33] using the $348 \mathrm{~F}-884 \mathrm{R} 16 \mathrm{~S}$ rRNA gene primer set. To confirm that potential PCR inhibitors were not coextracted, all samples were tested in parallel with the universal $16 \mathrm{~S}$ rRNA gene primer set 341F/907R [36, 37]. All samples from the site showed positive results with the universal primer set indicating that the assay would detect putative dechlorinating phylotypes in abundances greater than the detection limit of $2 \times 10^{2}$ gene copies $\mu \mathrm{L}^{-1}$. The enumerated 16S rRNA genes copies from the cPCR assay were normalized to the dry weight content of the soil sample. One $16 \mathrm{~S}$ rRNA gene copy per cell was assumed based on the genome sequences of Dehalococcoides ethenogenes [38] and CBDB1 [39]. DNA extraction efficiency was tested by extracting different amounts of homogenized soil and measuring the DNA concentration on a spectrophotometer at $280 \mathrm{~nm}$. The results showed linear extraction efficiency in the range from 0-4 g dry wt of soil (data not shown).

2.7. Detection of Potential Aerobic PCB Degrading Bacteria. Putative PCB degrading aerobic bacteria were detected by PCR amplification of the functional genes $b p h \mathrm{~A}$ and $b p h \mathrm{C}$, which encode the PCB transforming enzymes biphenyl dioxygenase and 2,3-dihydroxybiphenyl 1,2-dioxygenase, respectively. Detection of $b p h A$ was performed with primer set bphA40-F/bphA50-R [26], whereas detection of $b p h C$ was performed with primer set P42D-F/P43U-R [27]. PCR was conducted in $50 \mu \mathrm{L}$ reaction volumes using the following GeneAmp reagents (Applied Biosystems, Foster City, CA): $10 \mathrm{mM}$ Tris- $\mathrm{HCl}, 75 \mathrm{mM} \mathrm{KCl}, 0.2 \mathrm{mM}$ of each dNTP in a mix, $1.5 \mathrm{mM} \mathrm{MgCl} 2,2.5$ units of AmpliTaq DNA Polymerase, $50 \mathrm{pM}$ of each primer, $1 \mu \mathrm{L}$ of DNA template, and $34.5 \mu \mathrm{L}$ of nuclease free water. Amplification of the $b p h A$ fragment was performed as follows ( 40 cycles): denaturation at $45^{\circ} \mathrm{C}$ for $60 \mathrm{~s}$, primer annealing at $31-49^{\circ} \mathrm{C}$ for $3 \mathrm{~min}$, elongation at $72^{\circ} \mathrm{C}$ for $4 \mathrm{~min}$, and a final holding step at $4^{\circ} \mathrm{C}$. For amplification of the $b p h C$ fragment ( 35 cycles), the following conditions were applied: denaturation at $95^{\circ} \mathrm{C}$ for $30 \mathrm{~s}$, primer annealing at $35^{\circ} \mathrm{C}$ for $60 \mathrm{~s}$, elongation at $72^{\circ} \mathrm{C}$ for $3 \mathrm{~min}$, a final extension step at $72^{\circ} \mathrm{C}$ for $10 \mathrm{~min}$, and a final holding step at $4^{\circ} \mathrm{C}$. PCR products of the correct length were confirmed by electrophoresis using a $1.5 \%$ agarose gel. Burkholderia xenovorans LB400 [23] was used for verification of the PCR protocols for $b p h \mathrm{~A}$ and $b p h \mathrm{C}$ and as the positive control during PCR amplification.

2.8. Bioaugmentation in Microcosms. In total, $4 \mathrm{~g}$ of soil (wet weight) was inoculated into triplicate $10 \mathrm{~mL}$ volumes of anaerobically prepared mineral medium [41] in $25 \mathrm{~mL}$ anaerobe tubes sealed under $\mathrm{N}_{2}-\mathrm{CO}_{2}(80: 20)$ with Teflon septa. No electron donors were added except for the components in the medium $(0.0125 \% \mathrm{w} / \mathrm{v}$ cysteine $)$ and residual hydrogen $(\leq 5 \% \mathrm{v} / \mathrm{v})$ present in the atmosphere of the anaerobic glove box used for inoculating and sampling of the microcosms. D. chlorocoercia DF-1 was grown to approximately $10^{7}$ cells per $\mathrm{mL}$ with PCE, which was purged with $\mathrm{N}_{2} / \mathrm{CO}_{2}$ to remove residual PCE and chloroethene products that could result in "priming" of dechlorination activity. $2 \mathrm{~mL}$ of culture were inoculated into the soil microcosms. Nonbioaugmented controls included medium and soil containing indigenous microorganisms without DF1. Controls for abiotic activity containing medium, soil containing indigenous microorganisms, and DF- 1 were sterilized by sequential autoclaving for 1 hour on days 0,2 , and 4 .

2.9. Microbial Community Analysis. Community analyses were performed by denaturing HPLC (DHPLC) using a WAVE 3500 HT system (Transgenomic, Omaha, NE) and the $16 \mathrm{~S}$ rRNA gene primers $348 \mathrm{~F} / 884 \mathrm{R}$ as described previously [33]. The 16S rRNA gene fragments were analyzed in $20 \mu \mathrm{L}$ injection volumes and the fractions were collected in 96 well plates (Biorad, Hercules, CA). Fractions were dried using a Savant SpeedVac system (Thermo Electron Corporation, Waltham, MA) followed by dissolution in $15 \mu \mathrm{L}$ nuclease-free water. Each DHPLC fraction was sequenced in both the $5^{\prime}$ and $3^{\prime}$ direction with $250 \mathrm{pM}$ of primer $348 \mathrm{~F}$ or $884 \mathrm{R}$, respectively, in $5 \%$ DMSO to reduce effects from potential secondary structure using the BigDye Terminator v3.1 (Applied Biosystems, Foster City, CA) kit per the manufacturer's instructions and sequenced on an ABI $3130 \mathrm{XL}$ automated capillary DNA sequencer (Applied Biosystems, CA) as previously described [33]. The $16 \mathrm{~S}$ rRNA gene sequences and submitted gene sequences obtained from NCBI (http://ncbi.nlm.nih.gov/BLAST) were compiled and aligned using the automatic nucleic acid aligner in the BioEdit sequence alignment editor. A total of 13 sequences containing approximately 530 nucleotides were unambiguously aligned and used for calculation of trees by the neighbor joining and FITCH approaches using default settings in the PHYLIP software (http://evolution.genetics.washington.edu/phylip.html).

Bootstrap analyses (1000 replicates) were performed using the PHYLIP package.

2.10. Nucleotide Accession Numbers. The Genbank accession numbers for the $16 \mathrm{~S}$ rRNA sequences reported in this paper are JF412634-JF412646. 
TABLE 1: Analyses of the dry matter content, the total PCB concentration, the average number and percentage of chlorines less than 4 and 6 , respectively, and in soil samples and commercial Aroclor mixtures [40]. ${ }^{\mathrm{a}, \mathrm{b}, \mathrm{c}}$ refer to the homolog distribution profiles, where ${ }^{\mathrm{a}}$ is the most typical distribution, ${ }^{b}$ is the most dechlorinated, and ${ }^{c}$ is the least dechlorinated among the soil analyzed soil samples. Sample Meb9 was not collected.

\begin{tabular}{|c|c|c|c|c|c|}
\hline Location & Dry matter $(\mathrm{mg} / \mathrm{g})$ & PCB conc. (ppm) & Average no. of chlorines & $\leq 6$ chlorines $(\%)$ & $\leq 4$ chlorines $(\%)$ \\
\hline Meb1 & 18.92 & 34.8 & 6.52 & 52.1 & 0.4 \\
\hline $\mathrm{Meb}^{\mathrm{a}}$ & 17.54 & 264.6 & 6.47 & 53.6 & 0.5 \\
\hline Meb3 & 13.71 & 12.5 & 6.51 & 52.5 & 0.5 \\
\hline Meb4 & 28.25 & 36.6 & 6.54 & 50.7 & 0.4 \\
\hline Meb5 & 23.17 & 15.1 & 6.54 & 50.5 & 0.4 \\
\hline Meb6 & 26.61 & 3.1 & 6.43 & 54.7 & 1.7 \\
\hline Meb7 & 16.71 & 5.6 & 6.50 & 52.6 & 0.2 \\
\hline Meb8 & 23.71 & 45.3 & 6.54 & 50.5 & 0.5 \\
\hline Meb10 $0^{\mathrm{b}}$ & 15.91 & 4.6 & 6.36 & 55.9 & 4.3 \\
\hline Meb11 ${ }^{c}$ & 26.68 & 2.3 & 6.61 & 45.8 & 1.0 \\
\hline Meb12 & 33.61 & 8.2 & 6.48 & 52.3 & 2.4 \\
\hline Meb13 & 13.55 & 12.1 & 6.47 & 51.8 & 3.2 \\
\hline Meb14 & 27.34 & 12.3 & 6.47 & 52.3 & 2.6 \\
\hline Meb15 & 29.22 & 35.6 & 6.54 & 47.1 & 2.6 \\
\hline Meb16 & 15.20 & 9.1 & 6.48 & 50.9 & 2.7 \\
\hline Meb17 & 25.10 & 17.6 & 6.52 & 50.9 & 2.0 \\
\hline Meb18 & 36.72 & 11.3 & 6.50 & 50.9 & 2.7 \\
\hline Meb19 & 20.31 & 20.1 & 6.55 & 48.7 & 1.9 \\
\hline Meb20 & 18.60 & 72.7 & 6.54 & 51.7 & 0.3 \\
\hline Aroclor 1016 & - & - & 3.04 & 100.0 & 100.0 \\
\hline Aroclor 1232 & - & - & 2.41 & 100.0 & 94.1 \\
\hline Aroclor 1242 & - & - & 3.31 & 100.0 & 92.3 \\
\hline Aroclor 1248 & - & - & 3.97 & 100.0 & 82.2 \\
\hline Aroclor 1254 & - & - & 5.15 & 96.0 & 18.9 \\
\hline Aroclor 1260 & - & - & 6.39 & 56.7 & 0.6 \\
\hline
\end{tabular}

\section{Results}

3.1. Physical and Chemical Characterization of Soil Samples. Soil samples from 19 locations were collected in the center of the storm water drainage ditch bed and on each of the flanking banks at incremental distances from the inlet to approximately $365 \mathrm{~m}$ downstream in addition to five locations between 365 and $730 \mathrm{~m}$ downstream from the inlet (Figure 1). Soil samples collected from the banks were all moist, whereas both dry and moist soil samples were collected from the center of the ditch. Soil was not collected from the center of the ditch at the inlet because only 1$2 \mathrm{~cm}$ of soil was present above the bedrock due to erosion from heavy storm water events, but this layer increased in depth with distance from the inlet. Soil samples collected more than $365 \mathrm{~m}$ downstream were submerged in water at the time of sampling. The total PCB concentration at the 19 sampling sites ranged from $2.3-265 \mathrm{ppm}$ with an average of $32.8 \mathrm{ppm}( \pm 58.9 \mathrm{ppm})$, (Table 1$)$. The highest concentration was detected at the east bank nearest to the inlet (Meb2), whereas the lowest concentration was detected at the west bank sampling location Meb11. The average number of chlorines at each site ranged from 6.36-6.61, with a total average of $6.50( \pm 0.053)$, which is similar to the average of 6.4 observed for Aroclor 1260 (Table 1). The distribution of PCB homologs was similar to A1260 and in prior studies A1260 was reported to be the only Aroclor detected at this site [42]. In some of the samples, higher concentrations of tetra chlorinated congeners were observed (Table 1). The elevated levels of tetrachlorinated congeners detected did not coelute with any known chlorinated non-PCB compounds including pesticides and sulfur indicating that they were likely PCBs. The results suggest that in situ PCB dechlorination occurred to some extent in these samples.

3.2. Characterization of Indigenous Microbial Communities. Bacteria were detected in 18 of 19 samples using universal $16 \mathrm{~S}$ rRNA bacterial primers (Table 2). In contrast, putative anaerobic dechlorinating and putative aerobic degrading bacteria were detected in only ten samples using primers specific for dechlorinating Chloroflexi and $b p h A / b p h C$ genes, respectively (Table 2). At seven locations, both putative aerobic and anaerobic PCB transforming bacteria were detected in the same samples. The numbers of putative anaerobic dechlorinating bacteria ranged from $5 \cdot 10^{3}$ to 
TABle 2: Analyses of total bacteria, putative PCB dechlorinating and PCB degrading bacteria and the number of putative dechlorinating bacteria in soil samples. Sample Meb9 was not collected.

\begin{tabular}{|c|c|c|c|c|}
\hline \multirow{2}{*}{ Location } & \multicolumn{4}{|c|}{ Presence/absence of } \\
\hline & Bacteria & Dechlorinating bacteria & Aerobic PCB degraders & $\begin{array}{l}\text { No. of dechlorinating bacteria } \\
\left(16 \mathrm{~S} \text { copies } \cdot \mathrm{g} \mathrm{soil}^{-1}\right)\end{array}$ \\
\hline Meb1 & + & - & - & - \\
\hline Meb2 & + & - & - & - \\
\hline Meb3 & + & + & + & $<\mathrm{DL}^{\mathrm{a}}$ \\
\hline Meb4 & + & + & + & $3 \cdot 10^{4} \pm 2.8 \cdot 10^{4}$ \\
\hline Meb5 & + & + & + & $<\mathrm{DL}$ \\
\hline Meb6 & + & + & + & $3 \cdot 10^{6} \pm 2.8 \cdot 10^{6}$ \\
\hline Meb7 & + & + & + & $4 \cdot 10^{5} \pm 2.3 \cdot 10^{5}$ \\
\hline Meb8 & + & + & - & $3 \cdot 10^{5} \pm 2.8 \cdot 10^{5}$ \\
\hline Meb10 & + & - & + & - \\
\hline Meb11 & + & - & - & - \\
\hline Meb12 & + & - & - & - \\
\hline Meb13 & + & - & + & - \\
\hline Meb14 & + & + & + & $<\mathrm{DL}$ \\
\hline Meb15 & + & + & + & $<\mathrm{DL}$ \\
\hline Meb16 & + & - & + & - \\
\hline Meb17 & + & + & - & $<\mathrm{DL}$ \\
\hline Meb18 & + & + & - & $3 \cdot 10^{3} \pm 2.8 \cdot 10^{3}$ \\
\hline Meb19 & + & - & - & - \\
\hline Meb20 & + & - & - & - \\
\hline
\end{tabular}

Mean values and standard deviations \pm are given $(n=3)$.

${ }^{\mathrm{a}} \mathrm{DL}$ : detection limit $\geq 10^{2} 16 \mathrm{~S}$ copies/g wet soil.

$5 \cdot 10^{6}$ dechlorinating bacteria $\mathrm{g}^{-1}$ soil, whereas the numbers at several locations were below the detection limit for enumeration, but presence was detected. The number of putative aerobic degrading bacteria was not determined for this phylogenetically diverse group of bacteria.

The population of putative dechlorinating bacteria was examined by DHPLC in three samples where 16S rRNA gene copies were most abundant (Meb6, Meb7, and Meb8) and compared to the sequences of known PCB dechlorinating bacteria within the Chloroflexi group (Figure 2). Five of the 13 identified phylotypes grouped closely together within the clade of known Dehalococcoides sp. and the remaining eight phylotypes grouped within the broader o17/DF-1 Chloroflexi group. No trend was observed between the location of the samples and the identified phylotypes, since phylotypes from the three locations were located throughout the phylogenetic tree. This observation indicates the population of indigenous phylotypes was heterogeneous throughout the site.

3.3. Dechlorination Activities by Indigenous Communities. The indigenous dechlorination potential was examined in soil samples using $2,3,4,5,6-\mathrm{CB}$ as a surrogate, which is saturated with chlorines on one biphenyl ring. Activity was detected in six of the 19 samples (Table 3 ). The highest dechlorination rate $\left(6.93 \pm 5.33 \cdot 10^{-3} \mathrm{~mol} \% 2,3,4,5,6-\mathrm{CB}\right.$ $\times$ day $\left.^{-1}\right)$ was measured in Meb16 and the lowest $(0.93$ $\pm 1.70 \cdot 10^{-3} \mathrm{~mol} \% 2,3,4,5,6-\mathrm{CB} \times \mathrm{day}^{-1}$ ) in Meb17. The observed products of the dechlorination of 2,3,4,5,6$\mathrm{CB}$ were predominantly $2,3,4,5-\mathrm{CB} / 2,3,5,6-\mathrm{CB}$, but $2,3,6$ $\mathrm{CB}$, and 2,6-CB were detected in sample Meb10. The remaining 13 samples did not show any dechlorination activity after 200 days of incubation despite detection of putative dechlorinating bacteria by $\mathrm{CPCR}$ in some of the inactive samples.

3.4. Effects of Indigenous Contaminants on Activity. The absence of detectable dechlorination activity in some of the samples despite the detection of putative dechlorinating phylotypes was further examined to determine whether high concentrations of PCBs or other contaminants inhibited activity. Soil from inactive samples was mixed with biocatalytically active sediment from Baltimore Harbor, MD, which transforms $2,3,4,5,6-\mathrm{CB}$ to $2,4,6-\mathrm{CB}$ via reductive dechlorination at the two meta positions. For all tested samples including sediment from Baltimore Harbor, the lag phase was less than 50 days and the terminal plateau ranged between 6 and 46 mol\% 2,3,4,5,6-CB (Table 4). The dechlorination rates varied from $7-12 \cdot 10^{-3} \mathrm{~mol} \% 2,3,4,5,6$ $\mathrm{CB}$ day $^{-1}$, where the most active site had approximately $25 \%$ greater activity than observed in Baltimore Harbor sediment alone. This soil sample (Meb7) was collected furthest away from the inlet of the drainage ditch, had the highest number of putative dechlorinating bacteria, and had 


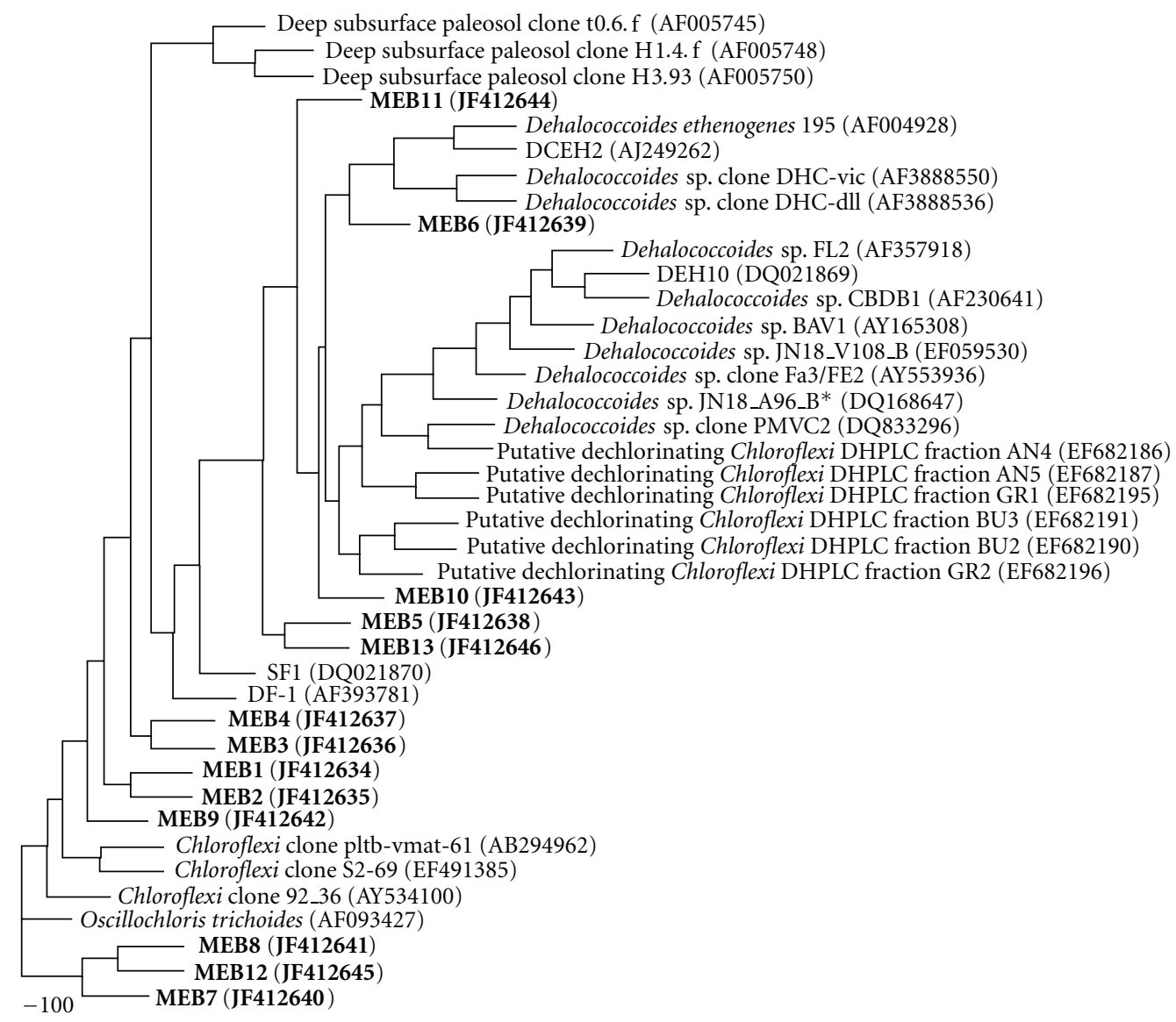

FIgURE 2: Phylogenetic tree showing the relationships between the dominant phylotypes identified in sediment samples Meb6, Meb7, and Meb8 (bold) and the closest dechlorinating species within the dechlorinating Chloroflexi group. Phylotypes from sample Meb6, Meb7 and Meb8 were located throughout the phylogenetic tree and did not show any relationship between the sample origins their phylogenetic relationship. Accession numbers are indicated in parentheses. The tree was calculated by the neighbor joining method and supported by FITCH [43]. The scale bar indicates 10 substitutions per 100 nucleotide positions.

a high water content compared to the rest of the samples. The dechlorination rates for the mixed samples were all higher or at levels similar to those observed in the activity assays (Table 3 ). In all samples tested, the end product of dechlorination was 2,4,6-CB, which is characteristic of $\mathrm{BH}$ activity rather than the tetrachlorinated congener products detected predominantly in indigenous ditch microcosms, indicating that the indigenous $\mathrm{BH}$ dechlorinating activities were dominant. A statistical evaluation (Student's $t$-test, $P<0.05)$ showed that statistically significant inhibition was found for only samples Meb6 and Meb18 (dechlorination plateau) and Meb17 (dechlorination rate and plateau).

3.5. Effect of Bioaugmentation. Bioaugmentation with a pure culture of the PCB dechlorinating bacterium DF-1 was tested in microcosms with soil from three locations containing approximately $5 \mathrm{ppm}$ (Meb10), $73 \mathrm{ppm}$ (Meb20), and $265 \mathrm{ppm}$ (Meb2) total weathered PCBs. These locations were selected based on the different concentrations of PCBs. The specific dechlorination of only doubly flanked chlorines by this organism could be readily distinguished from the dechlorination of single flanked and unflanked chlorines by the indigenous populations. Controls with indigenous populations without DF-1 and autoclaved controls showed no significant dechlorination. In the bioaugmented microcosms, significant dechlorination was observed for Meb10 (5 ppm), (Table 5). In addition to DF-1, a highly enriched culture of indigenous PCB dechlorinating microorganisms from MEB10 enriched with 2,3,4,5,6-PCB was also used to bioaugment Meb2, but no significant effect on dechlorination was observed. Evaluation of the changes in homolog distributions indicated that DF-1 was active in Meb10 (Figure 3), with significant reductions of hepta- and octachlorinated congeners and significant increases of tetra- and pentachlorinated congeners. The congeners that were significantly reduced were

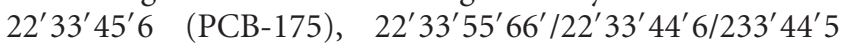

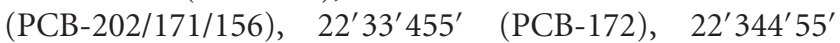
(PCB-180), 22' $33^{\prime} 44^{\prime} 5 / 233^{\prime} 44^{\prime} 56$ (PCB-170/190), and $22^{\prime} 344^{\prime} 55^{\prime} 6 / 22^{\prime} 33^{\prime} 44^{\prime} 56^{\prime}$ (PCB-203/196). All congeners that were dechlorinated significantly more than the control contained both double-flanked meta and para positioned congeners with the exception of PCB-175 and PCB-171 that only contained a double-flanked meta positioned chlorine 
TABLE 3: The potential dechlorination activity of the soil samples in microcosms. Locations not listed here did not show any dechlorination activity.

\begin{tabular}{|c|c|c|c|c|}
\hline Location & $\begin{array}{c}\text { Max rate } \cdot 10^{-3 a} \\
\left(\mathrm{~mol} \% 2,3,4,5,6-\mathrm{CB} \times \mathrm{day}^{-1}\right) \\
\end{array}$ & Lag phase $(d)$ & $\begin{array}{l}\text { PCB } 116 \text { remaining after } 200 \text { days } \\
(\text { mol\% } 2,3,4,5,6-C B)\end{array}$ & Dechlorination products \\
\hline Meb10 & $4.2(0.7)$ & $0-50$ & $46.0(7.0)$ & $\begin{array}{c}2,3,4,6-\mathrm{CB} / 2,3,5,6-\mathrm{CB}^{\mathrm{b}} \\
2,3,6-\mathrm{CB}, 2,6-\mathrm{CB}^{\mathrm{c}}\end{array}$ \\
\hline Meb12 & $4.2(4.1)$ & $0-130$ & $82.3(5.8)$ & $2,3,4,6-\mathrm{CB} / 2,3,5,6-\mathrm{CB}$ \\
\hline Meb13 & $3.4(3.8)$ & $0-150$ & $78.0(15.6)$ & $2,3,4,6-\mathrm{CB} / 2,3,5,6-\mathrm{CB}$ \\
\hline Meb16 & $6.9(5.3)$ & $0-105$ & $58.7(27.6)$ & $2,3,4,6-\mathrm{CB} / 2,3,5,6-\mathrm{CB}$ \\
\hline Meb17 & $0.9(1.7)$ & $0-200$ & $89.7(18.2)$ & $2,3,4,6-\mathrm{CB} / 2,3,5,6-\mathrm{CB}$ \\
\hline Meb19 & $3.0(5.0)$ & $0-200$ & $68.3(49.7)$ & $2,3,4,6-\mathrm{CB} / 2,3,5,6-\mathrm{CB}$ \\
\hline Negative control & 0.1 & - & 98 & - \\
\hline
\end{tabular}

${ }^{a}$ Mean values are given and figures in brackets are standard deviations $(n=3)$.

${ }^{\mathrm{b}}$ The products 2,3,4,6-CB/2,3,5,6-CB coeluted during GC analysis.

${ }^{\mathrm{c}}$ This product was detected in one of three replicate cultures $<5 \mathrm{~mol} \%$.

TABLE 4: Effect of inhibition on the dechlorination activity in microcosms using selected soil and sediment samples mixed $1: 1$ with actively dechlorinating sediment from Baltimore Harbor. Inhibition was determined $(P<0.05)$ for the dechlorination rate and terminal plateau. Lag phase is defined as not showing activity that is different from the autoclaved negative control.

\begin{tabular}{|c|c|c|c|c|c|c|}
\hline \multirow{2}{*}{ Location } & \multirow{2}{*}{ Lag phase $(d)$} & \multirow{2}{*}{$\begin{array}{l}\text { PCB } 116 \text { remaining after } 200 \text { days } \\
(\mathrm{mol} \% 2,3,4,5,6-\mathrm{CB})\end{array}$} & \multirow{2}{*}{$\begin{array}{l}\text { Dechlorination rate } \cdot 10^{-3} \\
\left(\% 2,3,4,5,6-\mathrm{CB} \text { day }^{-1}\right)\end{array}$} & \multirow{2}{*}{ End product } & \multicolumn{2}{|c|}{ Inhibition $(P<0.05)$} \\
\hline & & & & & Rate & Plateau \\
\hline Baltimore Harbor & $0-50$ & $5.7 \pm 4.5$ & $9.1 \pm 2.2^{b}$ & $2,4,6-\mathrm{CB}^{\mathrm{a}}$ & - & - \\
\hline Meb6 & $0-50$ & $31.3 \pm 15.9$ & $7.3 \pm 1.0$ & $2,4,6-\mathrm{CB}$ & No & Yes \\
\hline Meb7 & $0-50$ & $10.7 \pm 3.5$ & $12.4 \pm 1.1$ & $2,4,6-\mathrm{CB}$ & No & No \\
\hline Meb8 & $0-50$ & $21.0 \pm 19.2$ & $8.4 \pm 3.7$ & $2,4,6-\mathrm{CB}$ & No & No \\
\hline Meb17 & $0-50$ & $46.3 \pm 6.5$ & $7.5 \pm 2.2$ & $2,4,6-\mathrm{CB}$ & Yes & Yes \\
\hline Meb18 & $0-50$ & $45.7 \pm 10.1$ & $10.5 \pm 2.2$ & $2,4,6-\mathrm{CB}$ & No & Yes \\
\hline
\end{tabular}

${ }^{a}$ One tube showed additional terminal products such as 2,4-CB, 2,5-CB, and 2,6-CB.

${ }^{\mathrm{b}}$ Data are means \pm standard deviation $(n=3)$.

TABLE 5: Change in the number of chlorines per biphenyl over the five month incubation period for the bioaugmentation experiments with DF-1.

\begin{tabular}{lccc}
\hline \multirow{2}{*}{ Location } & \multicolumn{3}{c}{ Chlorines per biphenyl } \\
& Day 0 & \multicolumn{2}{c}{ Day 145 } \\
& & No DF1 & With DF1 \\
\hline Meb10 & $6.34 \pm 0.02$ & $6.30 \pm 0.19$ & $5.94 \pm 0.10$ \\
Meb20 & $6.42 \pm 0.02$ & $6.29 \pm 0.09$ & $6.30 \pm 0.04$ \\
Meb2 & $6.43 \pm 0.01$ & $6.42 \pm 0.01$ & $6.42 \pm 0.01$ \\
\hline
\end{tabular}

and PCB-202 that did not contain any double-flanked meta or para positioned chlorines. However, the latter congener coeluted with PCB-156 (50\%-50\% split) that contains both double-flanked meta and para positioned chlorines. In the samples Meb20 and Meb2 containing higher concentrations of total PCB, bioaugmentation with DF-1 did not show any significant effects (data not shown).

\section{Discussion}

Bacteria capable of aerobic PCB degradation are found ubiquitously in the soil environment and several have been isolated and identified that belong to genera such

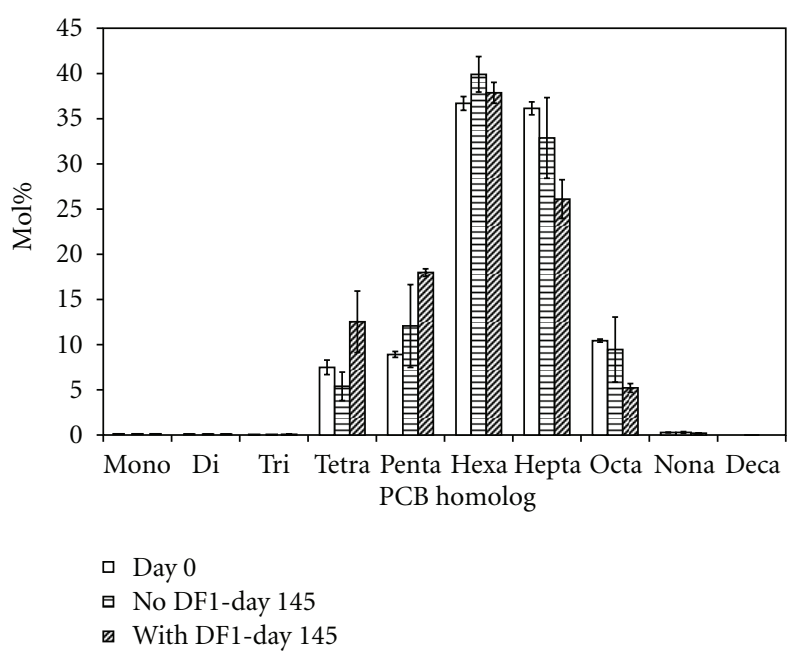

FIGURE 3: Homolog distribution showing the effect of DF-1 in the bioaugmentation experiment compared to effect of the indigenous population for Meb10.

as Pseudomonas, Burkholderia, Ralstonia, Achromobacter, Comamonas, Bacillus and Rhodococcus [25, 44]. Although anaerobic dechlorination activity has been detected in soils by activity based methods at several Canadian military installations such as Saglek, Labrador [45], Resolution Island, 
Nunavut [30], and Fort Albany, Ontario [46], anaerobic PCB dechlorinating bacteria have not been identified previously from soils. This is the first study to combine microbial community analysis and activity-based techniques on PCB impacted soils. The presence of active dechlorinating bacteria is an essential first step of the sequential degradation process that requires reduction of extensively chlorinated PCB congeners to less chlorinated congeners that can be subject to aerobic ring cleavage by microbial 2,3- and 3,4dioxygenase activity and can subsequently be mineralized by other aerobic microorganisms.

In the drainage ditch soil examined in this study, the PCB contamination originated predominantly from A1260 contamination [42]. The presence of tetra chlorinated homologs atypical of Aroclor 1260 combined with identification of the putative PCB dechlorinating phylotypes and detection of PCB dechlorination activity suggests that in situ dechlorination occurs at this site. The 13 identified phylotypes clustered within the dechlorinating Chloroflexi group, either within the the Dehalococcoides clade [47-49] within the broader Chloroflexi clade, which includes other confirmed PCB dechlorinating bacteria such as Dehalobium chlorocoercia DF-1 and strain o-17-group [50]. In two previous reports on bacterial communities in PCB contaminated soil, bacteria closely related to Proteobacteria, the HolophageAcidobacterium phylum, Actinobacteria, and Plantomycetales and Cytophagales were identified $[51,52]$. Interestingly, the dominant species included the genera Burkholderia and Variovorax together with Sphingomonas species, Rhodophila globiformis group members, and Acidobacterium capsulatum that aerobically degrade a variety of organic pollutants including PCBs. However, neither anaerobic dechlorinating bacteria nor any phylotypes related to the dechlorinating Chloroflexi were identified.

Prior to the current study, PCB dechlorinating bacteria have only been identified in sediments. Thus, detection of putative anaerobic dechlorinating bacteria and reductive dechlorination activity in the examined soil samples indicates that microbial dehalorespiration of PCBs also occurs in soil. Putative aerobic PCB degrading bacteria were also detected at several locations in the drainage ditch, which suggests that natural attenuation of PCBs could occur in soils by sequential anaerobic dechlorination followed by aerobic degradation. However, the large spatial heterogeneity of both anaerobic and aerobic phylotypes associated with PCB transformation could be an obstacle to bioremediation. Similar heterogeneity observations have been reported in studies of soils contaminated with heavy metals [9] and polycyclic aromatic hydrocarbons [11]. In the first study, it was found that samples collected within $1 \mathrm{~cm}$ distance could have a 10,000 fold difference in metabolic potential and that metal concentrations did not correspond with the metabolic potential [9]. In another report, microscale heterogeneities observed in $\mathrm{PAH}$ contaminated soil were attributed to the particle size of sand and silt fractions, which impacted the PAH concentrations and availability [11]. This corresponds with observations of the behavior between bacteria and clay minerals in soils contaminated with PCBs [12]. Here, it was observed that soil aggregates called "clay hutches" housed the bacteria creating a microhabitat, which would limit the PCB availability and constitute the main carbon source in an otherwise carbon limited environment. These observations of spatial heterogeneity on both a macro- and microscale are consistent with the observations of the spatial variability of bacteria involved in PCB transformation in soil in the current study.

The numbers of putative dechlorinating bacteria were 2 to 5 orders of magnitude lower in soils compared with sediments, where up to approximately $10^{8}$ bacteria per $\mathrm{g}$ sediment have been reported [33]. Dechlorination rates were lower in the soil compared to sediment indicating that the overall potential for dechlorination is reduced. The lack of correlation between the number of dechlorinating bacteria and the dechlorination rates in the soil samples might have been caused by localized environmental conditions. For example, most of the soil samples at the time of sampling were moist but were not submerged in water as sediment samples. In a study of simulated dredged sediment that was spiked with 300 ppm A1248, it was reported that the dechlorination activities were lowered when the water content was reduced, which caused a lag in the dechlorination of A1248 [53]. Degradation studies of other contaminants in soil such as petroleum hydrocarbons also show that moisture content in soil influences the degradation rate [54].

A possible consequence of the reduced moisture content in the soil samples could be exposure to oxygen that negatively influences anaerobic dechlorination. In a study of methanogenic granules capable of A1254 dechlorination, exposure to oxygen did not significantly influence the dechlorination activity [55]. In six months, $80 \%$ of the initial concentration of A1254 had been dechlorinated in samples that had been exposed to oxygen for one week. The reason for this rapid dechlorination could be the formation of biofilms in microniches that stay anaerobic despite the exposure to oxygen at the surface of the granule. Microniches in soil can result in spatial and temporal heterogeneity for parameters such as oxygen, $\mathrm{pH}$, redox, and nutrients as well as PCBs $[12,54]$. Thus, another factor affecting the spatial variation in dechlorination rates observed in the soil samples could be the heterogeneous moisture content affecting formation of biofilms and anaerobic microniches that support communities of dechlorinating bacteria.

Successful bioaugmentation of weathered Aroclor 1242 in soil with an enrichment culture from the Hudson River has been observed previously [56]. In the report, metadechlorination was observed after 19 weeks of incubation resulting in a reduction of the average chlorine content by 0.7 chlorines per biphenyl. Another report that evaluated the effect of sequential anaerobic-aerobic treatment of A1260 contaminated soil from Saglek, Labrador, Canada, [45] initiated with a dechlorinating enrichment, showed a decrease in the average chlorine content of 1.2 chlorines per biphenyl together with a significant homolog shift after three months of anaerobic bioaugmentation [45]. In the current study, bioaugmentation of A1260 contaminated soil with a pure culture of $D$. chlororcoercia has resulted in only 0.4 chlorines per biphenyl after 20 weeks. As expected, dechlorination of doubly flanked meta- and para-positioned chlorines was observed, but at least one product was 
observed that could not have been formed due to DF-1 activity, which suggests that $D$. chlororcoercia might have stimulated dechlorination of single-flanked chlorines by the indigenous dechlorinating population, possibly as a result of priming of the indigenous populations by intermediates products. Stimulation of dechlorinating activity after bioagumentation with $D$. chlororcoercia has been reported previously [57]. The relatively low rate of dechlorination in soil form Meb10 and lack of enhanced dechlorination at the two other bioaugmented sites might have been caused by inhibition by other contaminants such as metals and/or other organic contaminants [58].

In this study, the spatial distribution of bacteria involved in PCB transformation was investigated in Aroclor 1260 contaminated soil containing heavy metals and organic cocontaminants. The results showed that anaerobic PCB dehalorespiring bacteria were present and active. Detection of genes encoding biphenyl dioxygenase genes suggests that the potential exists for natural attenuation by sequential anaerobic dehalorespiration and aerobic degradation. Although a recent study demonstrated the potential for in situ treatment of PCB impacted sediment by bioaugmentation [57], the spatial heterogeneity inherent in soil in the current study had a profound effect on the ability to transform PCBs as only one of the bioaugmented samples showed positive effect. Strategies for effective in situ bioremediation of PCB-impacted soils may require additional remedial treatments such as flooding the soil prior to bioaugmentation to provide homologous water content, addition of a carbon source to create an adequately reduced environment for dehalorespiration, and precipitation of potentially inhibitory heavy metals or concurrent or sequential bioremediation with biocatalysts specifically target potentially inhibitory organic co-pollutants. The results illustrate some of the challenges associated with the development of in situ bioremediation strategies for PCB impacted soils.

\section{Acknowledgments}

This work was supported in part by the Office of Naval Research, U.S. Department of Defense, Grant N000014-031-0035 to K. R. Sowers and Grant N000014-03-1-0034 to H.D.May; U.S. Department of Defense, Strategic Environmental Research, and Development Program Project Numbers ER-1502 and ER-1492 to K. R. Sowers in addition to research funding to B. V. Kjellerup from Phillips Oral Health Care for development of DHPLC analysis methods. The authors thank Installation Restoration Program Manager Jeffrey A. Henning for his support and help to obtain samples and site information.

\section{References}

[1] R. D. Kimbrough, "Polychlorinated biphenyls (PCBs) and human health: An update," Critical Reviews in Toxicology, vol. 25, no. 2, pp. 133-163, 1995.

[2] A. Fischbein, J. Thornton, M. S. Wolff, J. Bernstein, and I. J. Selifoff, "Dermatological findings in capacitor manufacturing workers exposed to dielectric fluids containing polychlorinated biphenyls (PCBs)," Archives of Environmental Health, vol. 37, pp. 69-74, 1982.

[3] H. K. Ouw, G. R. Simpson, and D. S. Siyali, "Use and health effects of Aroclor 1242, a polychlorinated biphenyl, in an electrical industry," Archives of Environmental Health, vol. 31, no. 4, pp. 189-194, 1976.

[4] S. Safe, K. Connor, K. Ramamoorthy, K. Gaido, and S. Maness, "Human exposure to endocrine-active chemicals: Hazard assessment problems," Regulatory Toxicology and Pharmacology, vol. 26, pp. 52-58, 1997.

[5] S. T. Vater, S. F. Velazquez, and V. J. Cogliano, "A case study of cancer data set combinations for PCBs," Regulatory Toxicology and Pharmacology, vol. 22, no. 1, pp. 2-10, 1995.

[6] S. De Flora, M. Bagnasco, and P. Zanacchi, "Genotoxic, carcinogenic, and teratogenic hazards in the marine environment, with special reference to the Mediterranean Sea," Mutation Research, vol. 258, no. 3, pp. 285-320, 1991.

[7] K. Kannan, H. Nakata, R. Stafford, G. R. Masson, S. Tanabe, and J. P. Giesy, "Bioaccumulation and toxic potential of extremely hydrophobic polychlorinated biphenyl congeners in biota collected at a superfund site contaminated with Aroclor 1268," Environmental Science and Technology, vol. 32, no. 9, pp. 1214-1221, 1998.

[8] C. Backe, I. T. Cousins, and P. Larsson, "PCB in soils and estimated soil-air exchange fluxes of selected PCB congeners in the south of Sweden," Environmental Pollution, vol. 128, no. 1-2, pp. 59-72, 2004.

[9] J. M. Becker, T. Parkin, C. H. Nakatsu, J. D. Wilbur, and A. Konopka, "Bacterial activity, community structure, and centimeter-scale spatial heterogeneity in contaminated soil," Microbial Ecology, vol. 51, no. 2, pp. 220-231, 2006.

[10] W. A. Lead, E. Steinnes, J. R. Bacon, and K. C. Jones, "Polychlorinated biphenyls in UK and Norwegian soils: spatial and temporal trends," Science of the Total Environment, vol. 193, no. 3, pp. 229-236, 1997.

[11] W. Wilcke, W. Zech, and J. Kobža, "PAH-pools in soils along a PAH-deposition gradient," Environmental Pollution, vol. 92, no. 3, pp. 307-313, 1996.

[12] H. Lunsdorf, R. W. Erb, W. R. Abraham, and K. N. Timmis, "'Clay hutches': a novel interaction between bacteria and clay minerals," Environmental Microbiology, vol. 2, pp. 161-168, 2000.

[13] B. Ramakrishnan, T. Lueders, R. Conrad, and M. Friedrich, "Effect of soil aggregate size on methanogenesis and archaeal community structure in anoxic rice field soil," FEMS Microbiology Ecology, vol. 32, no. 3, pp. 261-270, 2000.

[14] J. L. M. Rodrigues, C. A. Kachel, M. R. Aiello et al., "Degradation of aroclor 1242 dechlorination products in sediments by Burkholderia xenovorans LB400(ohb) and Rhodococcus sp. strain RHA1(fcb)," Applied and Environmental Microbiology, vol. 72, no. 4, pp. 2476-2482, 2006.

[15] A. C. Alder, M. M. Häggblom, S. R. Oppenheimer, and L. Y. Young, "Reductive dechlorination of polychlorinated biphenyls in anaerobic sediments," Environmental Science and Technology, vol. 27, no. 3, pp. 530-538, 1993.

[16] P. B. Hatzinger and M. Alexander, "Effect of aging of chemicals in soil on their biodegradability and extractability," Environmental Science and Technology, vol. 29, no. 2, pp. 537545, 1995.

[17] J. A. Field and R. Sierra-Alvarez, "Microbial transformation and degradation of polychlorinated biphenyls," Environmental Pollution, vol. 155, no. 1, pp. 1-12, 2008. 
[18] D. H. Pieper and M. Seeger, "Bacterial metabolism of polychlorinated biphenyls," Journal of Molecular Microbiology and Biotechnology, vol. 15, no. 2-3, pp. 121-138, 2008.

[19] D. E. Fennell, I. Nijenhuis, S. F. Wilson, S. H. Zinder, and M. M. Häggblom, "Dehalococcoides ethenogenes Strain 195 Reductively Dechlorinates Diverse Chlorinated Aromatic Pollutants," Environmental Science and Technology, vol. 38, no. 7, pp. 2075-2081, 2004.

[20] L. Adrian, V. Dudkova, K. Demnerova, and D. L. Bedard, "Dehalococcoides sp. strain CBDB1 extensively dechlorinates the commercial polychlorinated biphenyl mixture aroclor 1260," Applied and Environmental Microbiology, vol. 75, pp. 4516-4524, 2009.

[21] L. A. Cutter, J. E. M. Watts, K. R. Sowers, and H. D. May, "Identification of a microorganism that links its growth to the reductive dechlorination of 2,3,5,6-chlorobiphenyl," Environmental Microbiology, vol. 3, no. 11, pp. 699-709, 2001.

[22] S. K. Fagervold, H. D. May, and K. R. Sowers, "Microbial reductive dechlorination of Aroclor 1260 in Baltimore Harbor sediment microcosms is catalyzed by three phylotypes within the Phylum chloroflexi," Applied and Environmental Microbiology, vol. 73, no. 9, pp. 3009-3018, 2007.

[23] P. S. G. Chain, V. J. Denef, K. T. Konstantinidis et al., "Burkholderia xenovorans LB400 harbors a multi-replicon, 9.73-Mbp genome shaped for versatility," Proceedings of the National Academy of Sciences of the United States of America, vol. 103, no. 42, pp. 15280-15287, 2006.

[24] E. Masai, A. Yamada, J. M. Healy et al., "Characterization of biphenyl catabolic genes of gram-positive polychlorinated biphenyl degrader Rhodococcus sp. strain RHA1," Applied and Environmental Microbiology, vol. 61, no. 6, pp. 2079-2085, 1995.

[25] K. Furukawa, "Molecular genetics and evolutionary relationship of PCB-degrading bacteria," Biodegradation, vol. 5, no. 34, pp. 289-300, 1994.

[26] M. J. Hoostal, G. S. Bullerjahn, and R. M. L. McKay, "Molecular assessment of the potential for in situ bioremediation of PCBs from aquatic sediments," Hydrobiologia, vol. 469, pp. 59-65, 2002.

[27] R. W. Erb and I. Wagner-Dobler, "Detection of polychlorinated biphenyl degradation genes in polluted sediments by direct DNA extraction and polymerase chain reaction," Applied and Environmental Microbiology, vol. 59, no. 12, pp. 4065-4073, 1993.

[28] A. C. Singer, E. S. Gilbert, E. Luepromchai, and D. E. Crowley, "Bioremediation of polychlorinated biphenyl-contaminated soil using carvone and surfactant-grown bacteria," Applied Microbiology and Biotechnology, vol. 54, no. 6, pp. 838-843, 2000.

[29] S. Di Toro, G. Zanaroli, and F. Fava, "Intensification of the aerobic bioremediation of an actual site oil historically contaminated by polychlorinated biphenyls (PCBs) through bioaugmentation with a non acclimated, complex source of microorganisms," Microbial Cell Factories, vol. 5, article no. 11, 2006.

[30] B. Kuipers, W. R. Cullen, and W. W. Mohn, "Reductive dechlorination of weathered Aroclor 1260 during anaerobic biotreatment of arctic soils," Canadian Journal of Microbiology, vol. 49, no. 1, pp. 9-14, 2003.

[31] Q. Wu, K. R. Sowers, and H. D. May, "Establishment of a polychlorinated biphenyl-dechlorinating microbial consortium, specific for doubly flanked chlorines, in a defined, sedimentfree medium," Applied and Environmental Microbiology, vol. 66, no. 1, pp. 49-53, 2000.
[32] U. Ghosh, A. S. Weber, J. N. Jensen, and J. R. Smith, "Relationship between PCB desorption equilibrium, kinetics, and availability during land biotreatment," Environmental Science and Technology, vol. 34, no. 12, pp. 2542-2548, 2000.

[33] B. V. Kjellerup, X. Sun, U. Ghosh, H. D. May, and K. R. Sowers, "Site-specific microbial communities in three PCB-impacted sediments are associated with different in situ dechlorinating activities," Environmental Microbiology, vol. 10, no. 5, pp. 1296-1309, 2008.

[34] M. Berkaw, L. Cutter, K. R. Sowers, and H. D. May, "Sitedependent ortho-, meta-, and para-dechlorination of PCBs by anaerobic estuarine and marine sediments enrichments," Bergen, Norway, 1996.

[35] T. R. Pulliam Holoman, M. A. Elberson, L. A. Cutter, H. D. May, and K. R. Sowers, "Characterization of a defined 2,3,5,6tetrachlorobiphenyl- orthodechlorinating microbial community by comparative sequence analysis of genes coding for $16 \mathrm{~S}$ rRNA," Applied and Environmental Microbiology, vol. 64, no. 9, pp. 3359-3367, 1998.

[36] G. Muyzer, E. C. De Waal, and A. G. Uitterlinden, "Profiling of complex microbial populations by denaturing gradient gel electrophoresis analysis of polymerase chain reactionamplified genes coding for 16S rRNA," Applied and Environmental Microbiology, vol. 59, no. 3, pp. 695-700, 1993.

[37] D. J. Lane, B. Pace, G. J. Olsen, D. A. Stahl, M. L. Sogin, and N. R. Pace, "Rapid determination of $16 \mathrm{~S}$ ribosomal sequences for phylogenetic analysis," Proceedings of the National Academy of Sciences of the United States of America, vol. 82, no. 20, pp. 6955-6959, 1985.

[38] R. Seshadri, L. Adrian, D. E. Fouts et al., "Genome sequence of the PCE-dechlorinating bacterium Dehalococcoides ethenogenes," Science, vol. 307, no. 5706, pp. 105-108, 2005.

[39] M. Kube, A. Beck, S. H. Zinder, H. Kuhl, R. Reinhardt, and L. Adrian, "Genome sequence of the chlorinated compoundrespiring bacterium Dehalococcoides species strain CBDB1," Nature Biotechnology, vol. 23, no. 10, pp. 1269-1273, 2005.

[40] O. Faroon, L. Samuel Keith, C. Smith-Simon, and C. De Rosa, Polychlorinated Biphenyls: Human Health Aspects, World Health Organization, Geneva, Switzerland, 2003.

[41] M. Berkaw, K. R. Sowers, and H. D. May, "Anaerobic ortho dechlorination of polychlorinated biphenyls by estuarine sediments from Baltimore Harbor," Applied and Environmental Microbiology, vol. 62, no. 7, pp. 2534-2539, 1996.

[42] Tetra Tech NUS I, 2005 Soil Sampling Summary Report for Site 9 - Stormwater Drainage Ditch, Bioremediation Pilot Study, Naval Support Activity, Pittsburg, Pa, USA, 2005.

[43] W. Ludwig, O. Strunk, R. Westram et al., "ARB: a software environment for sequence data," Nucleic Acids Research, vol. 32, no. 4, pp. 1363-1371, 2004.

[44] D. H. Pieper, "Aerobic degradation of polychlorinated biphenyls," Applied Microbiology and Biotechnology, vol. 67, no. 2, pp. 170-191, 2005.

[45] E. R. Master, V. W. M. Lai, B. Kuipers, W. R. Cullen, and W. W. Mohn, "Sequential anaerobic - Aerobic treatment of soil contaminated with weathered aroclor 1260," Environmental Science and Technology, vol. 36, no. 1, pp. 100-103, 2002.

[46] L. J. S. Tsuji, B. C. Wainman, I. D. Martin, J. P. Weber, C. Sutherland, and E. Nieboer, "Abandoned Mid-Canada Radar Line sites in the Western James region of Northern Ontario, Canada: a source of organochlorines for First Nations people?" Science of the Total Environment, vol. 370, no. 2-3, pp. 452-466, 2006.

[47] A. S. Waller, R. Krajmalnik-Brown, F. E. Loffler, and E. A. Edwards, "Multiple reductive-dehalogenase-homologous 
genes are simultaneously transcribed during dechlorination by dehalococcoides-containing cultures," Applied and Environmental Microbiology, vol. 71, pp. 8257-8264, 2005.

[48] D. L. Bedard, J. J. Bailey, B. L. Reiss, and G. Van Slyke Jerzak, "Development and characterization of stable sediment-free anaerobic bacterial enrichment cultures that dechlorinate aroclor 1260," Applied and Environmental Microbiology, vol. 72, no. 4, pp. 2460-2470, 2006.

[49] E. R. Hendrickson, J. A. Payne, R. M. Young et al., "Molecular analysis of Dehalococcoides 16S ribosomal DNA from chloroethene-contaminated sites throughout North America and Europe," Applied and Environmental Microbiology, vol. 68, no. 2, pp. 485-495, 2002.

[50] S. K. Fagervold, J. E. M. Watts, H. D. May, and K. R. Sowers, "Sequential reductive dechlorination of metachlorinated polychlorinated biphenyl congeners in sediment microcosms by two different Chloroflexi phylotypes," Applied and Environmental Microbiology, vol. 71, no. 12, pp. 80858090, 2005.

[51] B. Nogales, E. R. B. Moore, E. Llobet-Brossa, R. RosselloMora, R. Amann, and K. N. Timmis, "Combined use of $16 \mathrm{~S}$ ribosomal DNA and 16S rRNA to study the bacterial community of polychlorinated biphenyl-polluted soil," Applied and Environmental Microbiology, vol. 67, no. 4, pp. 1874-1884, 2001.

[52] B. Nogales, E. R. B. Moore, W. R. Abraham, and K. N. Timmis, "Identification of the metabolically active members of a bacterial community in a polychlorinated biphenylpolluted moorland soil," Environmental Microbiology, vol. 1, no. 3, pp. 199-212, 1999.

[53] Y. C. Cho, O. S. Kwon, R. C. Sokol, C. M. Bethoney, and G. Y. Rhee, "Microbial PCB dechlorination in dredged sediments and the effect of moisture," Chemosphere, vol. 43, no. 8, pp. 1119-1126, 2001.

[54] C. Davis, T. Cort, D. Dai, T. H. Illangasekare, and J. MunakataMarr, "Effects of heterogeneity and experimental scale on the biodegradation of diesel," Biodegradation, vol. 14, no. 6, pp. 373-384, 2003.

[55] M. R. Natarajan, H. Wang, R. Hickey, and L. Bhatnagar, "Effect of oxygen and storage conditions on the metabolic activities of polychlorinated biphenyls dechlorinating microbial granules," Applied Microbiology and Biotechnology, vol. 43, no. 4, pp. 733738, 1995.

[56] K. T. Klasson, J. W. Barton, B. S. Evans, and M. E. Reeves, "Reductive microbial dechlorination of indigenous polychlorinated biphenyls in soil using a sediment-free inoculum," Biotechnology Progress, vol. 12, no. 3, pp. 310-315, 1996.

[57] R. B. Payne, H. D. May, and K. R. Sowers, "Enhanced reductive dechlorination of polychlorinated biphenyl impacted sediment by bioaugmentation with a dehalorespiring bacterium," Environmental Science \& Technology, vol. 45, pp. 8772-8779, 2011.

[58] D. A. Abramowicz, M. J. Brennan, H. M. van Dort, and E. L. Gallagher, "Factors influencing the rate of polychlorinated biphenyl dechlorination in Hudson River sediments," Environmental Science \& Technology, vol. 27, pp. 1125-1131, 1993. 

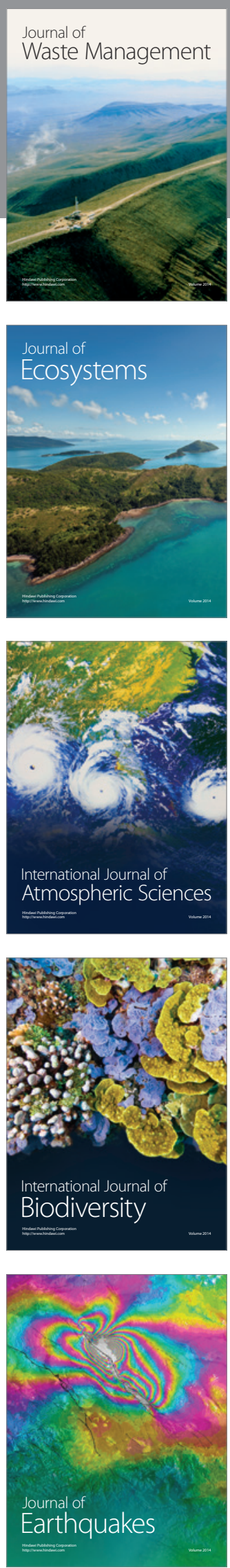
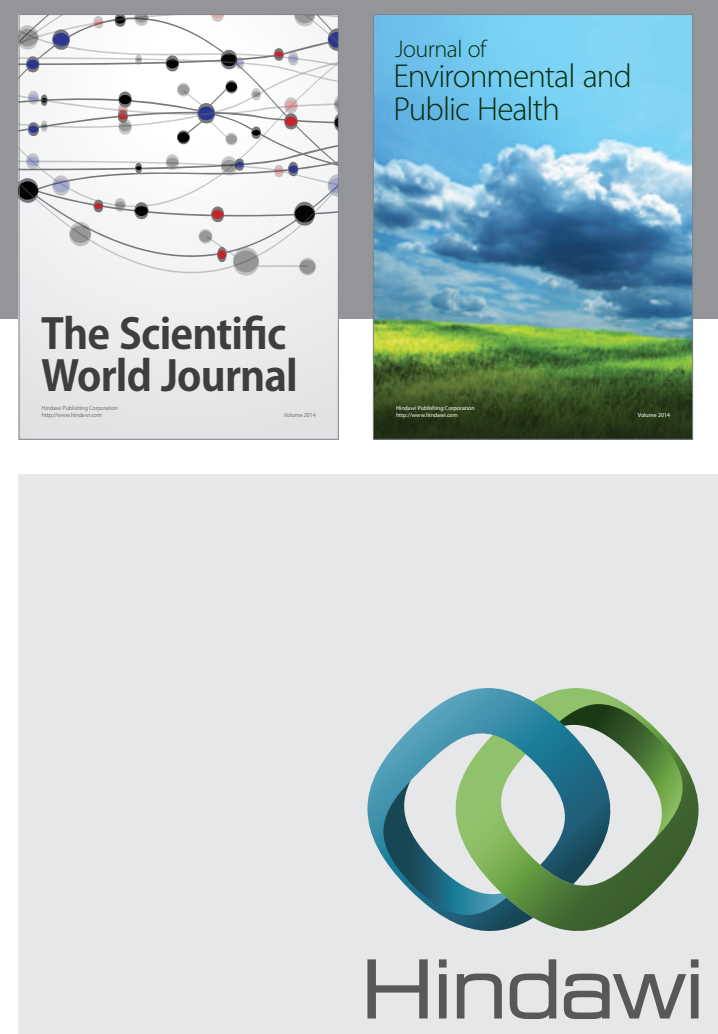

Submit your manuscripts at

http://www.hindawi.com
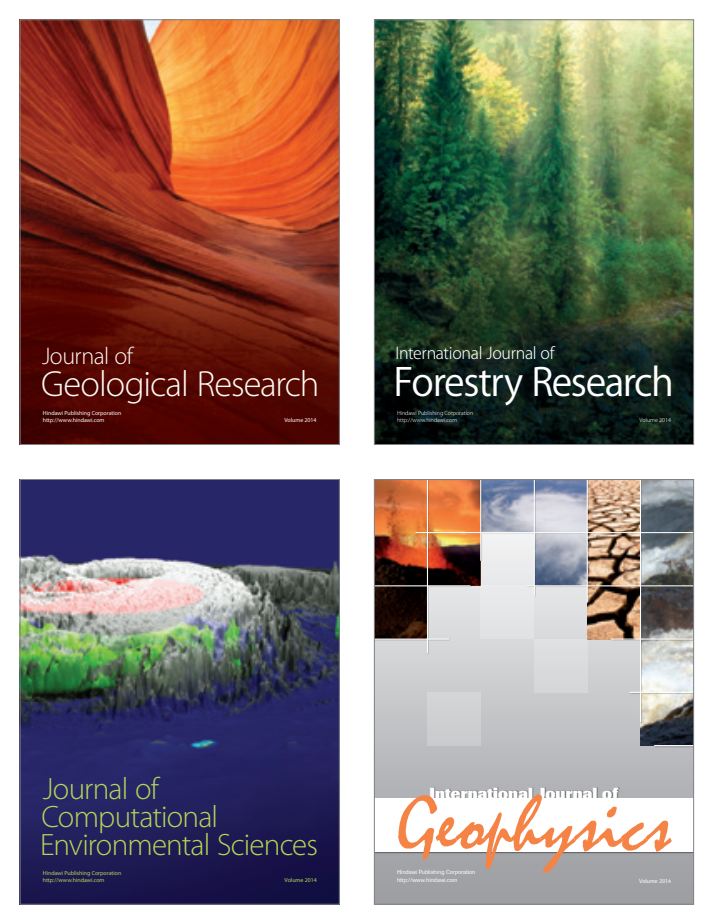
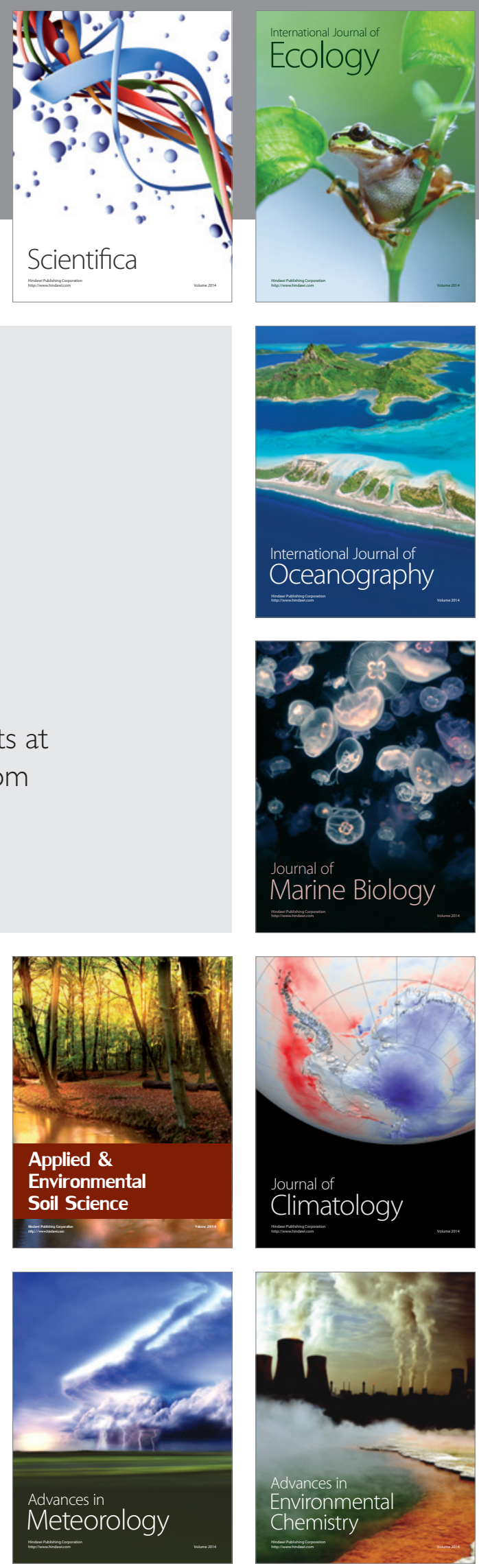